\title{
Teaching Diversity: Using a Multifaceted Approach to Engage Students
}

Arthur H. Auerbach, University of Southern California

ABSTRACT The traditional format for teaching courses to undergraduate students has long been that of lecture when professors speak and students listen. However, as times have evolved so too have the pedagogical methods in the classroom. In teaching a course on diversity and discrimination in the society, this instructor opted to combine several teaching methods as a means of not only conveying the substantive material to the class but, more importantly, engaging the students at an interactive learning level. By combining traditional lecture with watching/discussing documentaries and incorporating structured student debate, a dynamic learning environment was created. As a result of incorporating the students into every aspect of the class, the students learned from both the instructor and students alike. Thus, the use of this multifaceted approach created a positive and engaging learning environment for the whole class.

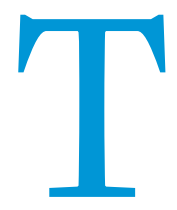

eaching techniques in political science have evolved over time. In the past, a traditionallecture format with students taking a purely passive role was the accepted protocol; now, both universities and students alike demand more from their instructors to maximize active learning that results in critical thinking. "Active learning theory holds that students internalize information best when they are directly involved in their own learning" (Greek 1995; Kunselman and Johnson 2004, 87). Although incorporating active learning methods to facilitate student learning is not a new concept (see Galbraith 1992; McAlpine 1992), combining various pedagogical methods within a single course to enhance active learning is unique. Using this strategy, this instructor taught a course "Politics of Human Differences: Diversity and Discrimination.”

Prior to taking on this assignment, this instructor primarily taught undergraduate courses dealing with law, which focused on government powers, civil rights, and liberties along with courses on judicial politics. A course primarily dealing with diversity within society thus set out quite a challenge. A course on the politics of human differences can be taught from a variety of perspectives and through many pedagogical means. Although the law often plays an important role with issues of diversity and discrimination, this course clearly needed to take a broader perspective. Likewise, the students who enrolled might include a number of students who had less interest and background on the law regarding this topic. This article presents the innovative approach undertaken to engage students on a topic that affects nearly every aspect of American life.

Arthur $\mathbf{H}$. Auerbach is an assistant professor (teaching) in the department of political science at the University of Southern California. He can be reached at aauerbac@usc.edu.

\section{GOALS FOR THE COURSE}

The goals for teaching this course went beyond simply ensuring that students learned the substantive material on specific subject matter. "There is a well-established literature on various pedagogical approaches to teaching and learning sufficient to convince most members of the academy that the classroom experience for students should advance beyond the typical college lecture format" (Sims 2006). A class on human differences needed to engage students at a very personal level. The real question was how to construct the course so that students not only learned important concepts and theories but to also enhance their engagement in the class. In other words, the instructor needed to create opportunities for students to bring their personal journeys, as well as those of their families and friends, into the classroom. To achieve such a lofty goal for the class a four-prong approach was selected: (1) focus on five specific elements (units) of diversity and discrimination in which each unit followed an identical structure, (2) include a traditional lecture format for a portion of each unit to ensure that students would complete the class with the relevant substantive material, (3) dedicate one class in each unit to watch a documentary on the specific topic for that unit in conjunction with instructor-lead discussion on the subject after the viewing, and (4) require interactive, structured student debate on various issues that fell within the subject-matter of each unit. This multifaceted approach proved to be not only an exceptionally useful means of teaching the substantive material but also inspired students to engage in class discussion as well as assist in educating the class on various important issues within those units of discussion. 


\section{CONTENT OF THE COURSE}

The initial challenge in creating this course was determining its content. A course such as this one could be structured in a variety of ways. Logically, it made sense to focus on five specific subject units that fell under the broad umbrella of diversity and discrimination. Four of the subject areas included discrimination based on race, gender, sexual orientation, and immigrant status. The intent in selecting these four particular topics was to combine two subject areas that have been long-standing issues in the United States in conjunction with two, more recent forms of discrimination. ${ }^{1}$ By looking at two forms of discrimination that have been part of the United States history for some time along with two more current forms students are able to cross-compare similarities and differences between subject areas based on when they took place in history. This comparison is an additional benefit for students.

The fifth and final unit of the course focused on ethnic cleansing. This unit stands alone from the other four for a specific reason: students study discrimination culminating with a discussion of how hatred and discrimination can reach the ultimate extreme of ethnic cleansing. With this basic framework in place, a proper pedagogical approach was necessary to ensure an active studentlearning environment. As discussed next, each unit was identically constructed in terms of format: two days of traditional lecture followed by one day of documentary review/discussion and two days of structured-student debate.

\section{TRADITIONAL LECTURE}

The first two classes within each unit were devoted to the traditional lecture format, which allowed students to read and discuss the literature on the topic. A traditional lecture format is still the most widely used method of teaching in universities across the United States (see Kunselman and Johnson 2004; Wells and McKinney 1997; Wolfer and Baker 200o). Although a lecture is focused on the various means of resolution including the educational system, media, labor market, and the political system. The class came to understand that each means of resolution was interconnected with the other requiring a broad response to racial discrimination.

Incorporating traditional lecture within each unit ensured that important concepts and theories would be covered in the course along with a robust discussion of the relevant literature that was assigned for that particular day. Although many criticize traditional lecture formats due to the passive nature (see Barr and Tagg 1995), students need not be passive listeners.

\section{DOCUMENTARY AND DISCUSSION}

The third day of each unit was dedicated to watching and discussing a documentary on the subject. At all levels of education instructors are increasingly using feature and documentary films in class to demonstrate various viewpoints and spur provocative classroom discussion (Marcus and Stoddard 2007; Stoddard 2009, 407). "Documentary films in particular are often created to examine controversial historical events in order to elicit social awareness of change" (Hess 2007; Stoddard 2009, 407-08). In this course, the selected documentaries examined a specific aspect of discrimination on the particular subject being discussed. Using multimedia within the classroom allowed students to see some of the realities of diversity and discrimination within society; discussions were not conducted in the abstract or purely from an academic perspective. Although some instructors may avoid using controversial issues in their classes for fear of being accused of indoctrination (Hess 2004), the deliberation of these issues is one of the most effective methods to educate students (see Barton and Levstik 2004; Hess 2002; Parker 2004; Stoddard 409-10).

During the unit on race, the documentary Color of Fear (Part 1) was shown. This controversial documentary showed eight North

\section{Although a lecture is often thought of as a one-way road with instructors speaking and students listening, the goal for this course was to create an in-depth conversation with the students, not only on the nature of the scholarship, but equally important, on the students' thoughts of the subject.}

often thought of as a one-way road with instructors speaking and students listening, the goal for this course was to create an in-depth conversation with the students, not only on the nature of the scholarship, but equally important, on the students' thoughts of the subject. Students were required to think critically about the scholarship relative to their own life experiences. Allowing students to draw on their own experiences provided for a bevy of discussion on each subject. In organizing the two lectures, the first lecture focused on the specific type of discrimination found within that unit, and the second lectured offered detailed discussion of relevant solutions to the problem.

For instance, during the racial discrimination unit, the class learned about three core concepts of racial discrimination, including individual, institutional, and structural discrimination (see Kamali 2009). Throughout the semester, these concepts were dealt with both in regard to race and also other forms of discrimination. During the second day of lecture in the race unit, the class
American men, including two African American, two Latino, two Asian American, and two Caucasian, who were gathered for a dia$\log$ about the state of race relations in the United States as seen through their own perspectives. The exchanges are sometimes dramatic and put in plain sight the pain caused by racism in the United States. In the gender unit, the class watched Women, A True Story. The Double Shift, in which women from around the world told their personal stories and discussed the daily discrimination that they faced. The documentary looked at issues surrounding economic equality for women and questioned whether women can achieve equality as long as they are expected to bear an unequal share of the work at home. The filmmakers followed a number of women to see how the double shift affects their life. Topics of the documentary include working mothers, equal pay for equal work, valuation of housework, sex discrimination in the workplace (glass ceiling), women as disposable labor, women entrepreneurs, and political activism. 
In the unit on discrimination based on sexual orientation, the class watched the Academy Award-nominated documentary Outrage. ${ }^{2}$ This film delivered a critical indictment of closeted politicians who actively campaign against the lesbian, gay, bisexual, and transgender (LGBT) community of which they covertly are part. Outrage reveals the hidden lives of some of our nation's most powerful policy makers, detailing the harm they have inflicted on millions of Americans, and examines the media's complicity in keeping their secrets. During the unit on discrimination based on national origin (immigration), Farmingville was shown that discusses the hate-based attempted murders of two Mexican day laborers that threw a small Long Island town into national headlines, unmasking a new front line in the border wars: suburbia. For nearly a year, the filmmakers lived and worked in Farmingville, New York, so they could capture first-hand the stories of residents, day laborers, and activists on all sides of the debate. This powerful film is more than a story about illegal immigration. Ultimately, it challenges viewers to ask what the "American Dream" really means. In the final unit of the class, the PBS series On Our Watch was shown regarding the genocide and ethnic cleansing in Darfur, Sudan. After the genocide in Rwanda and the ethnic cleansing in Srebrenica, the world said, "never again" and then came Darfur. Frontline produced an eight-chapter historical series on genocide and ethnic cleansing in Darfur, Sudan, and the failure of the United Nations and the world to anything about it.
Johnson 2004, 87). Although lecture is still the most widely used method of teaching within universities, combining effective teaching strategies can motivate students to become creative in the learning environment (Kunselman and Johnson 2004, 88; Wells and McKinney 1997; Wolfer and Baker 2000).

The process of debate as a teaching tool is a long and honored tradition. A common denominator among "great teachers" is the recognition that the value of the debate element in the educational process also emanates from the premise that teaching (focusing on the transmission of knowledge) and educating (focusing on the transmission of long-term skills and attitude) are two sides of the same coin (Vo and Morris 2006, 315). "To the extent that stimulating critical thinking on the part of the learner is an essential part of the mind-cultivating process, debating definitely has a role to play in collegiate education" (Vo and Morris 2006, 315-16). Involvement and participation provide valuable opportunities for direct engagement with the issues or materials under consideration. Thus, methodical observations suggest that the debate process proves to be helpful in creating a participatory environment (Vo and Morris 2006, 316; e.g., Green and Klug 1990). Furthermore, intellectual conflict serves as a foundation of effective teaching because it engages and involves the students, whose attention may otherwise "drift off to other things" during a passive, traditional lecture format (Johnson, Johnson, and Smith 2000; Vo and Morris 2006, 316).

\section{The process of debate as a teaching tool is a long and honored tradition. A common denominator among "great teachers" is the recognition that the value of the debate element in the educational process also emanates from the premise that teaching (focusing on the transmission of knowledge) and educating (focusing on the transmission of long-term skills and attitude) are two sides of the same coin.}

The key to using documentaries in the classroom was to allow enough time for student/instructor discussion after the showings. After the class viewed the documentaries, immediately discussing these provided not only focused review on the specific topic but also tapped into the students' emotional response. To ensure adequate reflection of each documentary, students were required to submit a three-to-four-page write-up on one of the five documentaries shown throughout the course. The write-up focused on the strengths and weaknesses of the arguments presented in the film along with their own critical views of the subject matter.

\section{STRUCTURED STUDENT DEBATE}

The final component of each unit within the course, and perhaps the most unique aspect of this format, was the structured student debate throughout the semester. As noted earlier, students tend to retain information from a course when that class incorporates active learning. "Active learning creates a classroom atmosphere of cooperative learning where students learn not only from the instructor but also from each other" (Greek 1995; Kunselman and Johnson 2004, 87). This practice produces critical thinking, engages problem solving, and promotes communication skills. Moreover, active learning also results in the cultivation of leadership skills and an improved self-esteem (Greek 1995, 104; Kunselman and
Organization is the key to orchestrating the debate series within a class of 40 students. During the first week of the semester, all students were required to sign-up for a debate within one of the five units. The days when the debates took place were identified in the syllabus so students could select both the topic area and the date of their debate. Students enjoyed this flexibility, because it gave them control over their schedules. Many students can anticipate when their schedules will get busy during the semester with midterms and various other projects, thus by allowing students to select the date of their debate schedule conflicts are resolved. ${ }^{3}$ Two weeks prior to the debate day, the four students who were scheduled to debate (two students per debate issue) and the instructor met to select the debate topics. Prior to that meeting students were told to conduct some basic research on the topic area and bring two to three issues to the meeting. By requiring students to bring possible issues to the pre-debate meeting, students took ownership over the debate topic, which furthers their interest in the subject.

The goal of the meeting was to select two issues that would be debated along with matching-up students based on their respective interest. Note that the instructor omits any discussion on the specific debate issues during the lecture days leading up to the debates. Thus, students become the educators for the class on these specific issues. In addition to selecting topics and positions 
on those topics, students were required to prepare a position paper. Requirements for the position paper were listed in a handout. The position paper requirements included 6-to-8-pages in length (double-spaced) wherein students give a brief introduction with a clear and concise thesis statement, an overview of the issue, three to five points in support of their position, one to two points on the anticipated counter-arguments, and a brief conclusion summing up their position. Students were informed that the position paper assignment required outside scholarly research, which acted as the basis for their position. The handout also included the date the paper had to be uploaded onto the university website (Blackboard). Position papers had to be uploaded three days prior to the day of the debate so that the instructor had an opportunity to read the position papers and prepare questions for the students who were debating. Furthermore, the debaters had an opportunity to read their opponent's papers as well as the remainder of the class who would attend the debates. Excluding the debate teams, the rest of the class were required to submit two questions dents in universities not only find this format dissatisfying but also counterproductive. Although many professors are undoubtedly brilliant in thought, such thoughts do not always translate to education. For these reasons, using various pedagogical methods in a single class is a promising way to educate. The strengths for using multiple methods are several-fold. First, active learning enhances the learning experience. As both Dewey (1939) and Baker (1955) noted long ago, active student engagement with a subject provides an effective venue for starting to learn how to explore and think (Vo and Morris 2006, 316). Common sense dictates that students take more away from a class that they have personal interest in as well as having an instructor who presents the material in an interesting and dynamic fashion. Second, the use of multimedia in the classroom provides alternative perspectives for class discussion and engagement. The old adage "a picture is worth a thousand words" cannot be overstated enough with regard to education on controversial issues within society. It is one thing to read about discrimination from books and journals, but it is clearly another to see the

\section{Allowing students to not only participate in the process of education but also to take on a key component of educating creates a new and different environment in the classroom.}

per position paper and upload them onto Blackboard the day before the debate. Failure to submit questions negatively affected students participation grade in the class.

During the debate, each student presented their respective position for approximately 10 to 15 minutes. The instructor questioned the students on the nature of their positions. By questioning students throughout their presentations, students moved away from their prepared remarks and were able to clarify their thoughts on the issues. Such questioning also gave the instructor a better sense of the students' true understanding of the issues. After each student presented his or her position on his or her particular issue, each debating student was permitted to ask a question of the other. Allowing the debating students to question each other ensures that each debating student is actively listening to the other during the debate and also helps focus the students on the crux of the issue. Then, after the debating students addressed their opponents' concerns, the instructor called on at least one student from the audience to offer a question that he or she had posted on Blackboard. Thereafter, the other students could question either debater. Allowing the class to engage the debating students moved the class from a passive position to actively engaging them in the class discussion. Often the length of the class discussion on the particular topic exceeded the time that the debating students were actually conducting the debate. In the end, an in-depth discussion between the debating students and the class continued while the instructor acted as a moderator.

Using this format to teaching a diversity class was successful. Students completed the course learning from scholarship, from their instructor, and, equally important, from their fellow students.

\section{DISCUSSION}

The goal of teaching this course using a multifaceted approach, in a word, was balance. For far too long, college professors have relied solely on their intellect as the means of engaging their students. In some instances, using such a tactic is sufficient, but today many stu- impact of discrimination in society on film.

Lastly, allowing students to participate actively in the education process creates an entirely new dynamic for a classroom, one that if structured correctly benefits not only the students but the instructor as well. A student-centered learning environment fits well in classes involved in discussing controversial policy issues that can provide fodder for robust learning activities (Sims 2006, 1).

Student-centered learning can increase students' ability to think critically about such issues as capital punishment, police brutality, the disproportionate representation of minorities in the criminal justice system, due process and the Patriot Act, etc. The list is endless. Conversely, an instructor-centered classroom environment, one that is dominated by the traditional lecture bombardment of students with endless definitions and factoids, is likely to neglect the need to have students react to the subject matter in ways that could facilitate higher order thinking (Sims 2006, 1).

Allowing students to not only participate in the process of education but also to take on a key component of educating creates a new and different environment in the classroom.

Although there are many attributes to constructing a course in this manner, with these strengths come some inherent weaknesses. First, a class structure such as this one creates the opportunity for motivated students to engage in active learning. At the same time, those students who are less motivated may find opportunities to disengage from the course. For instance, during the two debate days within each unit, eight students were presenting their position papers for discussion. This means that 32 other students in a class of 40 were not presenting papers and could take a passive role in class. To combat this possibility, everyone in the class was required to download the debate position papers from Blackboard and submit their questions on each paper. Students were made aware up-front that all papers posted on Blackboard constitute testable material for the midterm and final exams. This tactic is by no means a foolproof method to ensure that students 
were prepared before each debate, but it did assist in that endeavor. A second potential weakness to this structure was that students watched a documentary in each unit that runs typically from 60 to 90 minutes. Once again students took on a passive role when watching documentaries. That being said, discussion on the documentary immediately after watching the film quickly shifted the students from a passive role to an active role. Additionally, the documentaries were also considered testable material and one or more of the films could be included on exams.

The last concern centers around requiring every student to participate in the debate. There are students who do not like public speaking, even in a small class size. Public speaking is often thought of as an acquired taste. Some students take to it immediately while others do so begrudgingly. No matter their perspective, clearly at least some students will not be pleased about the requirement of not only debating their fellow students but their instructor as well. To deal with the concerns of those students who do not enjoy the experience, the instructor must inform the class from the outset about the debate requirement. Students should always be given the opportunity to drop a course if the structure of the class is not to their liking. It is equally important that the class be informed of how the debates will be conducted. After students learned that the debate was more of conversation between the student and the instructor as well as the class, concerns about the pressure of a presentation often faded away. Whether students like it or not, public speaking is a crucial component in the educational process and in the working world. The sooner students experience public speaking, the better off they will be. Anytime a new and creative pedagogical structure is used in a classroom, both positive and negative effects will be discovered. The goal should always be to promote the positives and minimize the negatives to the best of one's ability. In this particular class, this goal appears to have been achieved.

\section{CONCLUSION}

Education at the collegiate level has been undergoing a shift in terms of process for some time. Where once instructors spoke and students listened, today students demand more from their educational experience. For this reason, educators must use their creative capabilities to engage their students in a productive manner. Combining both older techniques, such as structured student debate, with newer technological advances is one way to bridge this gap. Although the construction of this course is a step in the right direction, it is by no means an end to this conversation. In the future, additional innovation can and should be done to further the education at the collegiate level. For the diversity class, for example, one possible addition would be to require students to interview persons who have encountered discrimination in their life. By requiring students to speak with persons who have actually experienced discrimination, students will relate better the theories presented in the classroom with the realities of discrimination in the real world. Thus, the use of a multifaceted approach to teaching a policy course such the "Politics of Human Differences: Diversity and Discrimination" was a useful structure and one that can be applied in a host of other courses.

\section{NOTES}

1. One would be remiss to omit discussions on race and gender in light of their historical importance in the United States. Yet, based on personal experience, these topics often do not resonate with the majority of the current generation of 18-to-24-year-old college students. It can be surmised that many college age students believe that issues relating to race and gender have largely been addressed by society and thus these issues are not thought of as being on the front-line of society. For this reason, race and gender were included in the course along with other more current issue areas of discrimination.

2. In 2009, when this instructor first taught the course, the class watched the Life and Times of Harvey Milk. Outrage had not yet been released for public use. Although the documentary on Harvey Milk's life provided a platform for discussing discrimination against the LGBT community, Outrage proved to be a better vehicle for the ensuing discussion.

3. Inevitably, some students may not get their first choice in terms of the debate topic or the date of their debate. However, after students select a topic and date, they are allowed to trade with another student as long as they notify the professor.

\section{REFERENCES}

Baker, M. C. 1955. Foundations of John Dewey's Education Theory. New York: Kings Crown Press.

Barr, R., and J. Tagg. 1995. "From Teaching to Learning: A New Paradigm for Undergraduate Education." Change 17: 12-25.

Barton, K., and L. Levstik. 2004. Teaching History for the Common Good. Mahwah, NJ: Lawrence Erlbaum.

Dewey, J. 1939. Experience and Education. New York: Macmillan.

Galbraith, M. 1992. "Nine Principles of Good Facilitation." Adult Learning 3 (6): 10-11, 20.

Greek, C. 1995. "Using Active Learning Strategies in Teaching Criminology: A Personal Account." Journal of Criminal Justice Education 6 (1): 153-64.

Green, C. S., and H. G. Klug. 1990. "Teaching Critical Thinking and Writing through Debates: An Experimental Evaluation.” Teaching Sociology 18: 462-71.

Hess, D. 2002. "Teaching Controversial Public Issues Discussions: Learning from Skilled Teachers." Theory and Research in Social Education 30 (1): 10-41.

Hess, D. 2004. "Controversies about Controversial Issues in Democratic Education." PS: Political Science and Politics 27 (2): 257-61.

Hess, D. 2007. "From Banished to Brother Outsider, Miss Navajo to An Inconvenient Truth: Documentary Films as Perspective-Laden Narratives." Social Education $71(4): 194-99$.

Johnson, D. W., R. T. Johnson, and K.A. Smith. 200o. "Constructive Controversy: The Educative Power of Intellectual Conflict." Change 32 (1): 28-38.

Kamali, Masound. 2009. Racial Discrimination-Institutions Patterns and Politics. New York: Routledge.

Kunselman, Julie C., and Katherine A. Johnson. 2004. "Using the Case Method to Facilitate Learning." College Teaching 52 (3): 87-92.

Marcus, A., and J. Stoddard. 2007. "Tinseltown as Teaching: Hollywood Film in the High School History Classroom." The History Teacher 40 (3): 303-30.

McAlpine, L. 1992. "Using Journals as Professional Conversations.” Adult Learning $3(4): 15$.

Parker, W. 2004. Teaching Democracy: Unity and Diversity in Public Life. New York: Teachers College Press.

Sims, Barbara. 2006. "Creating a Teaching and Learning Environment in Criminal Justice Courses That Promotes Higher Order Thinking." Journal of Criminal Justice Education 17 (2): 336.

Stoddard, Jeremy D. 2009. "The Ideological Implications of Using 'Educational' Film to Teach Controversial Events." Curriculum Inquiry 39(3): 407-33.

Vo, Han X., and Robert L. Morris. 2006. "Debate as a Tool in Teaching Economics: Rationale, Technique, and Some Evidence." Journal of Education for Business 81 (6): 315-20.

Wells, J. B., and M. K. McKinney. 1997. "Assessing Criminal Justice Student Learning Styles for Multimedia Instruction." Journal of Criminal Justice Education 8 (1): 1-18.

Wolfer, L., and T. E. Baker. 20oo. "Teaching Organized Crime Patterns: An Active Learning Approach." Journal of Criminal Justice Education 11(1): 79-96. 